\title{
A randomised controlled trial of increasing fruit and vegetable intake and how this influences the carotenoid concentration and activities of PON-1 and LCAT in HDL from subjects with type 2 diabetes
}

Jane-Ann Daniels ${ }^{1}$, Ciara Mulligan ${ }^{2}$, David McCance ${ }^{2}$, Jayne V Woodside ${ }^{1}$, Christopher Patterson ${ }^{1}$, lan S Young ${ }^{1}$ and Jane McEneny ${ }^{*}$

\begin{abstract}
Background: High density lipoproteins (HDL) have many cardioprotective roles; however, in subjects with type 2 diabetes (T2D) these cardioprotective properties are diminished. Conversely, increased fruit and vegetable (F\&V) intake may reduce cardiovascular disease risk, although direct trial evidence of a mechanism by which this occurs in subjects with T2D is lacking. Therefore, the aim of this study was to examine if increased F\&V consumption influenced the carotenoid content and enzymes associated with the antioxidant properties of HDL in subjects with T2D.

Methods: Eighty obese subjects with T2D were randomised to a 1- or $\geq 6$-portion/day F\&V diet for 8-weeks. Fasting serum was collected pre- and post-intervention. $\mathrm{HDL}$ was subfractionated into $\mathrm{HDL}_{2}$ and $\mathrm{HDL}_{3}$ by rapid ultracentrifugation. Carotenoids were measured in serum, $\mathrm{HDL}_{2}$ and $\mathrm{HDL}_{3}$ by high performance liquid chromatography. The activity of paraoxonase-1 (PON-1) was measured in serum, $\mathrm{HDL}_{2}$ and $\mathrm{HDL}_{3}$ by a spectrophotometric assay, while the activity of lecithin cholesterol acyltransferase (LCAT) was measured in serum, $\mathrm{HDL}_{2}$ and $\mathrm{HDL}_{3}$ by a fluorometric assay.

Results: In the $\geq 6$ - vs. 1-portion post-intervention comparisons, carotenoids increased in serum, $\mathrm{HDL}_{2}$ and particularly $\mathrm{HDL}_{3}$ ( $(\mathrm{a}$-carotene, $\mathrm{p}=0.008$; $\beta$-cryptoxanthin, $\mathrm{p}=0.042$; lutein, $\mathrm{p}=0.012$; lycopene, $\mathrm{p}=0.016$ ), as did the activities of PON-1 and LCAT in $\mathrm{HDL}_{3}(p=0.006$ and 0.044 , respectively).
\end{abstract}

Conclusion: To our knowledge, this is the first study in subjects with T2D to demonstrate that increased F\&V intake augmented the carotenoid content and influenced enzymes associated with the antioxidant properties of HDL. We suggest that these changes would enhance the cardioprotective properties of this lipoprotein.

Clinical trial registration: ISRCTN21676269

Keywords: Type-2 diabetes, Fruit and vegetables, High density lipoprotein, Carotenoids, Paraoxonase-1, Lecithin cholesterol acyltransferase

\footnotetext{
* Correspondence: j.mceneny@qub.ac.uk

${ }^{1}$ Centre for Public Health, Queen's University Belfast, Pathology Building,

Grosvenor Road, Belfast BT12 6BJ, UK

Full list of author information is available at the end of the article
} 


\section{Background}

Cardiovascular disease (CVD) is the leading cause of morbidity and mortality in Western societies, whose incidence is augmented by T2D [1]. In 2008, diabetes was the direct cause of $17 \%$ of all CVD related deaths [2]. Conversely, high density lipoproteins (HDL) are normally associated with reduced CVD risk, as these lipoproteins have many antiatherogenic properties; including their antioxidant and reverse cholesterol transport (RCT) capabilities. Furthermore, HDL stimulates glucose uptake and fatty acid oxidation, opposing insulin resistance [3]. However, in subjects with T2D the function of HDL may be defective, as hyperglycaemia increases lipid peroxidation [4], while the release of the inflammatory marker serum amyloid A (SAA) from hypertrophic adipocytes also impacts on the antiinflammatory and antioxidant properties of HDL [5]. Thus the main enzymes associated with HDL's antioxidant function, paraoxonase-1 (PON-1) and lecithin cholesterol acyltransferase (LCAT), with this latter enzyme also being involved in the maturation of HDL, may be altered to a pro-atherogenic phenotype in dysfunctional HDL $[6,7]$.

Therefore, interventions that reduce the risk of diabetes and CVD, such as increased fruit and vegetable $(\mathrm{F} \& \mathrm{~V})$ intake, are highly desirable. Although the relationship between F\&V intake and the incidence of T2D is not fully understood, there is substantial support for increased intake to reduce diabetes and CVD risk. In this regard, the study of Villegas et al. [8] reported that vegetables were protective against the development of T2D, while, in a population without diabetes, Panagiotakos et al. [9] identified that subjects consuming vegetables for more than 3 days per week had a $70 \%$ decreased risk of CVD and, furthermore, that an increase of one portion of fruit per day decreased CVD risk by $10 \%$. In support of this, Cooper et al., [10] recently showed that increased vegetable intake and a variety of fruit reduced diabetes risk. Therefore, from the above evidence, it appears that increased F\&V intake would be protective against the development of diabetes and the associated CVD complications.

The protective effect of F\&V may be related to their rich antioxidant content, as these have been linked to a lower diabetes risk and the suppression of the inflammatory response related to diabetes and CVD development $[11,12]$. Many F\&V derived lipid phase antioxidants, such as the carotenoids, are transported in the circulation by lipoproteins, including HDL, and in the case of lycopene, has been shown to influence the cardioprotective properties of HDL. In fact, in a previous study by our group we found that among middle-aged, moderately overweight subjects, lycopene intake, via supplement or as a lycopene-rich diet, lead to antiatherogenic increases in the activities of PON-1 and LCAT within HDL [11]. Additionally, another study identified that serum carotenoids and the activity of serum-PON-1 increased following a Mediterranean-like diet, while the inflammatory marker C-reactive protein (CRP) decreased [13]. Overall, these studies suggest that the antioxidants within $F \& V$ may, in part, be responsible for their cardioprotective effects.

However, although the literature is suggestive that increased F\&V intake is beneficial to subjects with T2D, no study has investigated the relationship between increased F\&V intake and the enzymes associated with HDL in these subjects. Therefore, the aim of this study was to examine if increased F\&V intake had the potential to enhance the antiatherogenic properties of this lipoprotein in subjects with T2D.

\section{Methods}

\section{Study population}

This study was a secondary analysis of blood samples collected from subjects with T2D following a randomised controlled F\&V intervention. The study consisted of 80 subjects who were recruited from the diabetes outpatient clinics at the Regional Centre for Endocrinology and Diabetes at the Royal Victoria Hospital, Belfast, UK. All subjects were obese $\left(B M I>30 \mathrm{~kg} / \mathrm{m}^{2}\right)$, and aged between 40 and 70 years. In each case T2D was controlled by diet or oral hypoglycaemic therapy, which was maintained for the duration of the study. Prior to the 8-week intervention period all subjects underwent a 4-week run-in period, where they were asked to consume 1-portion of $F \& V /$ day. One portion of $F \& V$ is defined by the Food Standards Agency and the National Health Service as $80 \mathrm{~g}$ [14]. Following this, subjects were randomly assigned to 1 of 2 treatment groups $(n=40$ / group): a low F\&V group, where they continued to consume 1-portion of $F \& V /$ day, or a high $F \& V$ group, were they consumed $\geq 6$-portions of $F \& V /$ day. Fasting blood samples were obtained following the wash-out phase (week-0) and post-intervention (week-8), serum was isolated by centrifugation and stored in aliquots at $-80^{\circ} \mathrm{C}$ until required for analysis. Figure 1 illustrates the study design for this intervention. F\&V supplementation was similar to that of a normal diet, therefore, did not pose any health risk. Specific advice was also given to ensure a similar calorific and macronutrient intake to their normal diet, while weekly contact encouraged compliance. To assess compliance, two 7-day food diaries were completed during the run-in period and during the intervention (results not shown). Subjects selected the F\&Vs of their choice, which were delivered weekly from a local supermarket during the 8-week intervention period. They were also offered advice on suitable storage and cooking methods for the F\&Vs to minimise their 


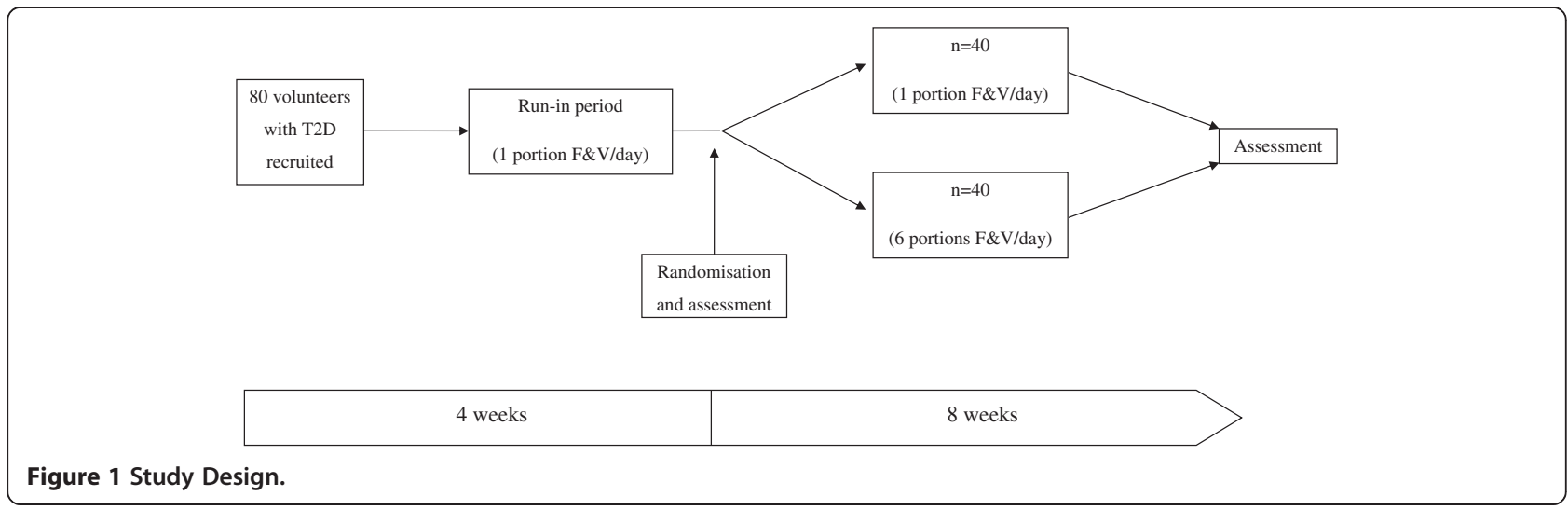

degradation. This study was approved by the ethics committee of Queen's University Belfast, and all subjects gave written informed consent.

\section{Exclusion criteria}

Exclusion criteria included any acute coronary/cerebrovascular event, surgery within the previous 3-months; pregnant or lactating females; oral anticoagulant therapy; excess alcohol consumption ( $>2$ units per day for females; $>3$ units per day for males); food sensitivities that would interfere with the F\&V consumption; medical conditions or dietary restrictions that would substantially limit the ability of the subject to complete the study requirements; and ingestion of oral vitamin/antioxidant supplements in the 4-weeks prior to the wash-out phase.

\section{Isolation of $\mathrm{HDL}_{2}$ and $\mathrm{HDL}_{3}$ from serum}

$\mathrm{HDL}_{2}$ and $\mathrm{HDL}_{3}$ were harvested from freshly thawed serum by rapid ultracentrifugation, according to the method of McPherson et al., (2007) [15]. This consisted of a 3-step, 6-hour long procedure. HDL samples were stored at $-80^{\circ} \mathrm{C}$ and at this temperature HDL is stable for up to one year (results not shown), all samples were batch analysed.

\section{Apolipoprotein (apo) Al concentration}

Apo AI was determined by a single radial immunodiffusion method, as previously described [16].

\section{Carotenoid concentration}

Lipid soluble carotenoids, including $\alpha$-carotene, $\beta$-carotene, $\beta$-cryptoxanthin, lutein, lycopene and zeaxanthin were measured in serum, $\mathrm{HDL}_{2}$ and $\mathrm{HDL}_{3}$ by reverse-phasehigh performance lipid chromatography (HPLC) with diode array detection, as previously described [17].

\section{PON-1 activity}

The arylesterase activity of PON-1 was measured in serum, $\mathrm{HDL}_{2}$ and $\mathrm{HDL}_{3}$. This assay was based upon the ability of PON-1 to hydrolyse phenylacetate, and was an adaption of the method of Hasselwander et al., 1999 [18], utilising $5 \mu \mathrm{L}$ of serum, $200 \mu \mathrm{L}$ of $\mathrm{HDL}_{2}$ and $20 \mu \mathrm{L}$ of $\mathrm{HDL}_{3}$. One unit of arylesterase activity $(\mathrm{U})$ is defined as $1 \mu \mathrm{mol}$ of phenol generated per minute [18].

\section{LCAT activity}

The activity of LCAT was measured in serum, $\mathrm{HDL}_{2}$ and $\mathrm{HDL}_{3}$ using a commercially available fluorometric assay (RB-LCAT, ROAR Biomedical, NY, USA), as per manufacturer's instructions. The LCAT assay required $5 \mu \mathrm{L}$ of serum, $\mathrm{HDL}_{2}$ or $\mathrm{HDL}_{3}$ per analysis.

\section{hsCRP and SAA concentration}

The concentration of serum high sensitive (hs)CRP was determined by immunoturbidimetry. While SAA was measured in serum, $\mathrm{HDL}_{2}$ and $\mathrm{HDL}_{3}$ by a commercially available ELISA (Invitrogen, Human SAA KHA0011C) and the analysis was performed on a Grifols TRITURUS automated ELISA system (Italy), as per the manufacturer's instructions, with the following modifications prior to analysis: serum was diluted 1:150, $\mathrm{HDL}_{2}$ 1:10 and $\mathrm{HDL}_{3} 1: 100$.

\section{Statistical analysis}

A retrospective power calculation for $\mathrm{HDL}_{3}$-lycopene and $\mathrm{HDL}_{3}-\mathrm{PON}-1$ activity indicated that a subject population of 20 per group was sufficient to give a $90 \%$ power at the $5 \%$ level of significance to detect a statistical difference between the groups. However, for completeness we have included all subjects in our analyses. Statistical analyses were performed using SPSS Statistics version 17.0. Variables were assessed for normality and logarithmically transformed where required. Between-group comparisons were analysed by an independent samples t-test. Within-group comparisons were analysed by a paired sample t-test. To adjust for potential confounders, an analysis of covariance was conducted, with final value of the variable of interest included as the dependent variable, the initial value of the variable of interest included as the covariate, and potential confounders, such 
as BMI, included in the model. All variables were summarised as mean (SEM) when normally distributed and as geometric mean (interquartile range) when normally distributed after logarithmic transformation. Correlations between variables were assessed by Pearson's twotailed bivariate analysis. Significance was set as $\mathrm{p}<0.05$ for all analyses.

\section{Results}

\section{Subject characteristics}

Initially 98 subjects were recruited into the study, 17 subjects withdrew during the run-in period prior to randomisation and 1 subject withdrew during the intervention period due to a family bereavement. A total of 80 subjects with T2D completed the 8-week intervention study. Six subjects had either pre- or post-intervention serum hsCRP levels $>10 \mathrm{mg} / \mathrm{l}$ and thus were excluded from further analyses. This was in accordance with American Heart Association guidelines [19] as a hsCRP of $>10 \mathrm{mg} / \mathrm{l}$ is taken as evidence of active infection or inflammation. Thus 74 subjects were included in the final analyses (Table 1). All baseline characteristics were comparable between the groups ( $p>0.05$ for all comparisons), and although there were more women randomised to the $\geq 6$-portion intervention $(n=15 / 39)$ compared to the number of women randomised to the 1-portion intervention $(n=7 / 35)$, this was not statistically different $(p=0.295)$. Following intervention, BMI was different between the groups, which was driven by the significant increase in BMI $\left(0.3 \mathrm{~kg} / \mathrm{m}^{2}\right)$ following the $\geq 6$-portion intervention $(p=0.001)$. However, the effect of this change in BMI was tested independently using an analysis of covariance for all subsequent statistical analyses and was found not to influence the results (data not shown). Additionally, $\mathrm{HbA}_{1 \mathrm{C}}$ decreased following the 1-portion intervention ( $p=0.032)$, although this was not continued in the between group comparisons $(\mathrm{p}>0.05)$.

\section{Fruit and vegetable consumption}

F\&V intake was calculated from two 7-day food diaries, where it was identified that $F \& V$ intake was significantly different in the $\geq 6$ - vs. 1 -portion comparisons $(\mathrm{p} \leq 0.001$ ) following intervention, which was driven by the significant increase in F\&V intake following the $\geq 6$-portion intervention [pre 1.4 (0.5) portions F\&V/day vs. post 5.2 (1.4) portions $\mathrm{F} \& \mathrm{~V} /$ day, $\mathrm{p} \leq 0.001$ ], which equated to a 3.8 (1.34) portion increase in $F \& V /$ day, while $F \& V$ intake did not change following the 1-portion intervention [pre $1.2(0.4)$ portions $\mathrm{F} \& \mathrm{~V} /$ day vs. post $1.5(0.9)$ portions $\mathrm{F} \& \mathrm{~V} /$ day, $\mathrm{p}=0.335$ ].

\section{Dietary intake}

Following intervention, total energy was not different in the $\geq 6$ - vs. 1-portion comparisons ( $p>0.05$; Table 2). However, carbohydrate and total sugar were significantly different between the groups $(\mathrm{p}<0.05$ and $\mathrm{p} \leq 0.001$, respectively), which were driven by the significant increase following the $\geq 6$-portion intervention $(\mathrm{p}<0.05$ and $\mathrm{p} \leq 0.001$, respectively).

\section{Apo Al concentration}

Following intervention, apo AI was not different in the between or within group comparisons ( $p>0.05$ for all comparisons, results not shown).

Table 1 Subject characteristics pre and post intervention

\begin{tabular}{|c|c|c|c|c|c|}
\hline \multirow[t]{2}{*}{ Characteristic } & \multicolumn{2}{|c|}{1 Portion Group ( $n=35)$} & \multicolumn{2}{|c|}{6 Portion Group $(n=39)$} & \multirow{2}{*}{$\begin{array}{l}\text { Trend for change } \\
\text { between groups }\end{array}$} \\
\hline & Pre & Post & Pre & Post & \\
\hline Male Sex (\%) & 80 & - & 61.5 & - & 0.295 \\
\hline BMI $\left(\mathrm{kg} / \mathrm{m}^{2}\right)$ & $30.1(0.6)$ & $30.1(0.7)$ & $30.7(0.6)$ & $31.0(0.6)^{d}$ & 0.012 \\
\hline Age (years) & $59.9(1.23)$ & - & $58.2(1.47)$ & - & 0.263 \\
\hline Glucose (mmol/L) & $8.0(6.6,9.6)$ & $8.5(7.5,22.3)$ & $8.2(7.0,8.9)$ & $8.9(8.3,18.8)$ & 0.587 \\
\hline Insulin (mU/L) & $13.7(9.4,21.2)$ & $14.6(7.5,22.3)$ & $11.9(8.0,17.4)$ & $16.8(8.3,18.8)$ & 0.470 \\
\hline $\mathrm{HbA1C}(\%)$ & $7.2(0.2)$ & $7.1(0.2)^{c}$ & $7.1(0.2)$ & $7.1(0.2)$ & 0.068 \\
\hline Duration of diabetes (years) & $6.7(0.9)$ & - & $5.2(0.7)$ & - & $>0.05$ \\
\hline Triglycerides (mmol/L) & $1.82(1.2,2.1)$ & $1.69(1.1,2.1)$ & $1.73(1.1,2.0)$ & $1.79(1.2,2.2)$ & 0.168 \\
\hline Total cholesterol (mmol/L) & $3.95(0.13)$ & $3.86(0.11)$ & $3.87(0.12)$ & $3.93(0.12)$ & 0.640 \\
\hline HDL cholesterol (mmol/L) & $1.24(0.05)$ & $1.20(0.05)$ & $1.25(0.05)$ & $1.23(0.05)$ & 0.194 \\
\hline Lipid lowering therapy (\%) & 94 & - & 95 & - & $>0.05$ \\
\hline Diabetic therapy (diet) (\%) & 5 & - & 8 & - & $>0.05$ \\
\hline Oral hypoglycaemic therapy (\%) & 86 & - & 80 & - & $>0.05$ \\
\hline
\end{tabular}

Results expressed as mean (SD) or when data was not normally distributed as geometric mean (interquartile range).

The following subscripts indicate - $a ; p \leq 0.05$ for baseline comparison between groups: $b ; p \leq 0.001$ for baseline comparison between groups: $c$ : $p \leq 0.05$ for within group comparison: $\mathrm{d} ; \mathrm{p} \leq 0.001$ for within group comparison. 
Table 2 Total energy intake and macronutrient intake pre and post F\&V intervention

\begin{tabular}{|c|c|c|c|c|c|}
\hline & \multicolumn{2}{|c|}{1 Portion $(n=35)$} & \multicolumn{2}{|c|}{6 Portions $(n=39)$} & \multirow{2}{*}{$\begin{array}{l}\text { Trend for chang } \\
\text { between groups }\end{array}$} \\
\hline & Pre & Post & Pre & Post & \\
\hline Energy (kcal/day) & $1601(370)$ & $1646(424)$ & $1652(494)$ & $1748(486)$ & $>0.05$ \\
\hline Carbohydrate (g/day) & $181(29)$ & $186(25)$ & $184(25)$ & $215(25)^{d}$ & $<0.05$ \\
\hline Total sugars (g/day) & $58(28)$ & 61 (22) & $57(17)$ & $99(25)^{e}$ & $\leq 0.001$ \\
\hline
\end{tabular}

Results expressed as mean (SD) or when data was not normally distributed as geometric mean (interquartile range).

The following subscripts indicate - $a ; p \leq 0.05$ for baseline comparison between groups: $b ; p \leq 0.001$ for baseline comparison between groups: $c$ : $p \leq 0.05$ for within group comparison: $\mathrm{d} ; \mathrm{p} \leq 0.001$ for within group comparison.

\section{Carotenoid concentration}

Following intervention, serum $\alpha$-carotene, $\beta$-cryptoxanthin, lutein and zeaxanthin increased in the $\geq 6$ - vs. 1-portion comparisons ( $\mathrm{p}<0.05$ for all comparisons); Table 3) which were driven by increases of $\sim 8 \%$ in $\alpha$ carotene $(\mathrm{p}=0.036), \sim 25 \% \quad \beta$-cryptoxanthin $(\mathrm{p}=0.001)$ and $\sim 25 \%$ lutein $(\mathrm{p}=0.003)$, and the borderline nonsignificant increase in zeaxanthin $(\mathrm{p}=0.067)$ following the $\geq 6$-portion intervention. In $\mathrm{HDL}_{2}, \beta$-cryptoxanthin increased in the $\geq 6$ - vs. 1-portion post-intervention comparisons $(\mathrm{p}<0.05)$, which was driven by the $\sim 47 \%$ increase in $\beta$-cryptoxanthin $(p=0.015)$ following the $\geq$ 6-portion intervention, additionally, lutein also increased in $\mathrm{HDL}_{2}$ following the $\geq 6$-portion intervention $(\mathrm{p} \leq 0.001)$. For $\mathrm{HDL}_{3}, \alpha$-carotene, $\beta$-cryptoxanthin, lutein and lycopene increased in the $\geq 6$ - vs. 1-portion post-intervention comparisons ( $\mathrm{p}<0.05$ for all comparisons), which were driven by an increase of $\sim 38 \%$ $\alpha$-carotene $(\mathrm{p}=0.001), \quad 32 \% \quad \beta$-cryptoxanthin $(\mathrm{p}=$ $0.041), \sim 9 \%$ lutein $(\mathrm{p}=0.006)$ and $\sim 27 \%$ lycopene ( $\mathrm{p}=0.015)$ following the $\geq 6$-portion intervention. Additionally, following the $\geq 6$-portion intervention there was a $\sim 30 \%$ increase in $\beta$-carotene $(\mathrm{p}=0.012)$ and $\mathrm{a} \sim 11 \%$ increase in zeaxanthin $(\mathrm{p}=0.004)$.

Table 3 Serum, $\mathrm{HDL}_{2}$ and $\mathrm{HDL}_{3}$ carotenoid antioxidants pre and post $\mathrm{F} \& \mathrm{~V}$ intervention

\begin{tabular}{|c|c|c|c|c|c|}
\hline \multirow[t]{2}{*}{ Antioxidant } & \multicolumn{2}{|c|}{1 Portion $(n=35)$} & \multicolumn{2}{|c|}{6 Portions $(n=39)$} & \multirow{2}{*}{$\begin{array}{l}\text { Trend for change } \\
\text { between groups }\end{array}$} \\
\hline & Pre & Post & Pre & Post & \\
\hline \multicolumn{6}{|l|}{ Serum $(\mu \mathrm{mol} / \mathrm{L})$} \\
\hline a-carotene & $0.028(0.004)$ & $0.028(0.005)$ & $0.029(0.003)$ & $0.032(0.004)^{c}$ & 0.047 \\
\hline$\beta$-carotene & $0.10(0.03)$ & $0.11(0.04)$ & $0.13(0.02)$ & $0.14(0.02)$ & 0.520 \\
\hline$\beta$-cryptoxanthin & $0.03(0.01)$ & $0.03(0.01)$ & $0.04(0.005)$ & $0.05(0.005)^{d}$ & 0.002 \\
\hline Lutein & $0.12(0.01)$ & $0.12(0.01)$ & $0.12(0.01)$ & $0.15(0.01)^{c}$ & 0.030 \\
\hline Lycopene & $0.28(0.04)$ & $0.31(0.05)$ & $0.35(0.05)$ & $0.34(0.04)$ & 0.820 \\
\hline Zeaxanthin & $0.03(0.003)$ & $0.03(0.003)$ & $0.03(0.003)$ & $0.04(0.002)$ & 0.020 \\
\hline \multicolumn{6}{|l|}{$\mathrm{HDL}_{2}$ (nmol/L) } \\
\hline a-carotene & $2.3(0.3)$ & $2.0(0.4)$ & $2.8(0.3)$ & $3.3(0.7)$ & 0.351 \\
\hline$\beta$-carotene & $5.5(1.1)$ & $6.3(1.5)$ & $7.0(1.1)$ & $7.8(0.1)$ & 0.971 \\
\hline$\beta$-cryptoxanthin & $2.0(0.5)$ & $1.7(0.5)$ & $1.9(0.4)$ & $2.8(0.5)^{c}$ & 0.006 \\
\hline Lutein & $5.5(0.9)$ & $5.9(0.9)$ & $5.9(0.6)$ & $7.6(0.7)^{c}$ & 0.182 \\
\hline Lycopene & $12.1(1.2)$ & $10.0(1.1)$ & $13.6(1.3)$ & $12.9(1.2)$ & 0.914 \\
\hline Zeaxanthin & $3.1(0.5)$ & $2.8(0.5)$ & $2.9(0.5)$ & $2.7(0.3)$ & 0.826 \\
\hline \multicolumn{6}{|l|}{$\mathrm{HDL}_{3}(\mathrm{nmol} / \mathrm{L})$} \\
\hline a-carotene & $8.1(1.2)$ & $8.5(1.2)$ & $7.8(1.1)$ & $10.8(1.7)^{d}$ & 0.008 \\
\hline$\beta$-carotene & $23.4(3.2)$ & $25.9(4.5)$ & $19.8(4.3)$ & $25.7(5.5)^{c}$ & 0.399 \\
\hline$\beta$-cryptoxanthin & $14.1(2.4)$ & $13.8(1.9)$ & $13.3(3.1)$ & $17.6(2.9)^{c}$ & 0.042 \\
\hline Lutein & $6.3(0.7)$ & $6.5(0.7)$ & $6.6(0.4)$ & $7.2(0.4)^{c}$ & 0.012 \\
\hline Lycopene & $33.1(4.3)$ & $30.3(3.5)$ & $29.3(4.1)$ & $37.2(4.8)^{c}$ & 0.016 \\
\hline Zeaxanthin & $10.5(0.9)$ & $10.7(0.9)$ & $9.7(1.1)$ & $10.8(1.2)^{c}$ & 0.166 \\
\hline
\end{tabular}

Results expressed as mean (SEM) or when data was not normally distributed as geometric mean (interquartile range).

The following subscripts indicate - $a ; p \leq 0.05$ for baseline comparison between groups: $b ; p \leq 0.001$ for baseline comparison between groups: $c ; p \leq 0.05$ for within group comparison: $\mathrm{d} ; \mathrm{p} \leq 0.001$ for within group comparison. 


\section{PON-1 activity}

Following intervention, serum-PON-1 activity was unchanged in the $\geq 6$ - vs. 1 -portion comparisons ( $p>0.05$; Table 4), however, serum-PON-1 activity increased by $\sim 7 \%$ ( $\mathrm{p} \geq 0.001$ ) following the $\geq 6$-portion intervention. In $\mathrm{HDL}_{2}, \mathrm{PON}-1$ activity was unchanged in the $\geq 6$ - vs. 1-portion comparisons $(\mathrm{p}<0.05)$ and following the 1 and $\geq 6$-portion interventions ( $p>0.05$ for both comparisons). However, in $\mathrm{HDL}_{3}$, the activity of PON-1 significantly increased in the $\geq 6$ - vs. 1 -portion comparison ( $\mathrm{p}<0.05)$, which was driven by the $\sim 13 \%$ increase in its activity following the $\geq 6$-portion intervention $(\mathrm{p} \leq 0.001)$, despite the $\sim 4 \%$ increase in its activity following the 1 -portion intervention $(\mathrm{p}=0.014)$.

\section{LCAT activity}

In serum, LCAT activity was unchanged in the $\geq 6$ - vs. 1-portion comparisons ( $>0.05$; Table 4). However, similarly to PON-1, the activity of serum-LCAT increased by $\sim 8 \%$ following the $\geq 6$-portion intervention $(\mathrm{p}=0.025)$. In $\mathrm{HDL}_{2}$, the activity of LCAT was unchanged in the $\geq 6$ - vs. 1-portion comparisons $(\mathrm{p}>0.05)$ and following the 1 and $\geq 6$-portion interventions ( $p>$ 0.05 for both comparisons). However, the activity of LCAT was increased in $\mathrm{HDL}_{3}$ in the $\geq 6$ - vs. 1-portion comparison $(\mathrm{p}<0.05)$, which was driven by the $\sim 8 \%$ increase in its activity following the $\geq 6$-portion intervention $(\mathrm{p}<0.001)$.

\section{hsCRP and SAA concentration}

Following intervention, serum hsCRP and serum-, $\mathrm{HDL}_{2^{-}}$and $\mathrm{HDL}_{3}$-SAA were similar in the $\geq 6$ - vs. 1-portion comparisons ( $\mathrm{p}<0.05$ for all comparisons; Table 4) and although SAA decreased by $\sim 32 \%$ following the $\geq 6$-portion intervention in $\mathrm{HDL}_{3}$, this was not significant $(\mathrm{p}=0.133)$.

\section{Correlations between change in $F \& V$ intake, change in carotenoid antioxidant levels and change in activity of HDL-associated enzymes}

Change in F\&V intake was positively correlated with change in $\mathrm{HDL}_{2}-\beta$-cryptoxanthin $(\mathrm{r}=0.312, \mathrm{p}=0.047), \quad \mathrm{HDL}_{3}$ $\alpha$-carotene $(\mathrm{r}=0.416, \mathrm{p}=0.005), \mathrm{HDL}_{3} \quad \beta$-cryptoxanthin $(\mathrm{r}=0.325, \mathrm{p}=0.032)$ and $\mathrm{HDL}_{3}$ lutein $(\mathrm{r}=0.317, \mathrm{p}=0.036)$. Additionally, change in $\mathrm{HDL}_{3} \beta$-cryptoxanthin positively correlated with change in $\mathrm{HDL}_{3}-\mathrm{PON}-1$ activity $(\mathrm{r}=0.258$, $\mathrm{p}=0.043)$.

\section{Discussion}

Carotenoids and the influence of increased F\&V intake This study has demonstrated that increased F\&V intake augmented serum carotenoid levels in this subject population, illustrating subject compliance and confirming previous reports in healthy and T2D subjects [20]. In addition, we have shown for the first time in a population with T2D that this increase led to a concomitant increase in the carotenoid content of $\mathrm{HDL}_{2}$ and $\mathrm{HDL}_{3}$, which was particularly apparent for $\alpha$-carotene,

Table 4 Serum, HDL 2 and HDL 3 PON-1 and LCAT activities and SAA and hsCRP concentrations pre and post F\&V intervention

\begin{tabular}{|c|c|c|c|c|c|}
\hline \multirow[t]{2}{*}{ Analyate } & \multicolumn{2}{|l|}{1 Portion $(n=35)$} & \multicolumn{2}{|l|}{6 Portions $(n=39)$} & \multirow{2}{*}{$\begin{array}{l}\text { Trend for change } \\
\text { between groups }\end{array}$} \\
\hline & Pre & Post & Pre & Post & \\
\hline \multicolumn{6}{|l|}{ Serum } \\
\hline PON-1 (U/mL) & $25.78(0.78)^{\mathrm{a}}$ & $25.75(0.78)$ & $26.53(0.81)$ & $28.05(0.79)^{d}$ & 0.155 \\
\hline LCAT ratio $(470 / 390)$ & $0.98(0.04)$ & $1.02(0.03)$ & $0.90(0.02)$ & $0.97(0.02)^{c}$ & 0.562 \\
\hline $\mathrm{SAA}(\boldsymbol{\mu g} / \mathrm{L})$ & $21180(6876,22894)$ & $20926(8898,22894)$ & $21484(6810,28645)$ & $20464(9020,31635)$ & 0.399 \\
\hline hsCRP (mg/L) & $2.30(1.06,2.96)$ & $2.19(0.98,2.33)$ & $2.17(0.97,2.70)$ & $2.34(1.22,3.47)$ & 0.527 \\
\hline \multicolumn{6}{|l|}{$\mathrm{HDL}_{2}$} \\
\hline PON-1 (U/mL) & $0.37(0.03)$ & $0.38(0.04)$ & $0.40(0.04)$ & $0.42(0.04)$ & 0.959 \\
\hline LCAT ratio $(390 / 470) \times 10^{-3}$ & $5.25(0.05)$ & $5.26(0.06)$ & $5.31(0.07)$ & $5.34(0.08)$ & 0.996 \\
\hline SAA $(\mu \mathrm{g} / \mathrm{L})$ & $1579(214,1188)$ & $1448(242,1107)$ & $1145(204,1120)$ & $1197(254,1196)$ & 0.228 \\
\hline \multicolumn{6}{|l|}{$\mathrm{HDL}_{3}$} \\
\hline PON-1 (U/mL) & $8.10(0.21)$ & $8.40(0.20)^{c}$ & $8.54(0.25)$ & $9.51(0.13)^{d}$ & 0.006 \\
\hline LCAT ratio $(390 / 470)$ & $0.89(0.02)$ & $0.90(0.02)$ & $0.87(0.01)$ & $0.94(0.02)^{d}$ & 0.044 \\
\hline SAA $(\mu \mathrm{g} / \mathrm{L})$ & $15834(7549,21352)$ & $17858(5236,23360)$ & $16211(5007,24087)$ & $12235(4006,18120)$ & 0.197 \\
\hline
\end{tabular}

Results expressed as mean (SEM) or when data was not normally distributed as geometric mean (interquartile range).

PON-1 - paroxonase-1: LCAT - lecithin cholesterol acyltransferase: SAA - serum amyloid A

LCAT activity was read fluorometrically at $390 \mathrm{~nm}$ and $470 \mathrm{~nm}$ and expressed as a ratio of the two. These two wavelengths represent the LCAT substrate hydrolysed and not hydrolysed. An increase in the ratio indicates increased LCAT activity.

The following subscripts indicate - $a ; p \leq 0.05$ for baseline comparison between groups: $b ; p \leq 0.001$ for baseline comparison between groups: $c$; $\leq \leq 0.05$ for within group comparison; ${ }^{d_{i}} \mathrm{p} \leq 0.001$ for within group comparison. 
$\beta$-cryptoxanthin, lutein and lycopene in $\mathrm{HDL}_{3}$. Furthermore, this lycopene result confirms our previous findings, where we identified that lycopene, which is the most potent single oxygen quencher among the natural carotenoids [21], increased in $\mathrm{HDL}_{2}$ and $\mathrm{HDL}_{3}$ following a lycopene rich diet [11]. Thus we suggest that the increase in the carotenoids identified in this current study would enhance the antioxidant properties of HDL, similarly to that reported in subjects with T2D following a high polyphenol diet, where plasma malondialdehyde, a frequently used indicator of lipid peroxidation [22] decreased in subjects consuming this diet [23]. Furthermore, in support of our findings phylloquinone, a lipidsoluble molecule that is found in green leafy plants, improves markers related to insulin resistance and diabetes [24] and, due to its ability to accept electrons, contributes to the antioxidant capacity of HDL, which we suggest may also be the case for the increased carotenoids identified in this current study. In addition, a Mediterranean-style diet has been suggested to be advantageous from a metabolic perspective in subjects with T2D [25] and may even modulate genetic predisposition in such subjects [26]. Thus, overall we suggest that the increased antioxidants within the HDL subfractions, particularly $\mathrm{HDL}_{3}$, the subfraction more closely associated with HDL's antioxidant properties [27,28], would have enhanced antiatherogenic potential in this T2D cohort.

\section{PON-1 and LCAT activities and the influence of increased $F \& V$ intake}

This F\&V intervention was also associated with significant increases in the activities of both PON-1 and LCAT, again confirming our previous findings following a lycopene rich diet [11]. Therefore, as one of HDL's main antiatherogenic function is to inactivate peroxidised lipids removed from apolipoprotein B-containing lipoproteins, due to the proton donating properties of PON-1 [29] and to a lesser extent LCAT [30], an increase in the activities of these enzymes would be thought of as antiatherogenic. Therefore, as the activity of serum-PON-1 has been reported to be lower in subjects with T2D [31], we have now shown that increased F\&V intake augmented its activity, in serum and particularly in $\mathrm{HDL}_{3}$, in this $\mathrm{T} 2 \mathrm{D}$ population, which was further supported by the positive correlation between the concentration of $\beta$-cryptoxanthin and the activity of PON-1 in $\mathrm{HDL}_{3}(\mathrm{r}=0.258, \mathrm{p}=0.043)$. These findings are in support of previous studies, where quercetin and glabridin were shown to protect PON-1 against copper-induced oxidation [29], while pomegranate juice (a rich source of carotenoids) was shown to increase its activity in healthy male subjects [32]. Overall, we suggest that the increase in the described antioxidants may have enhanced PON-1's proton donating properties and hence were responsible for the increase in its activity, especially in $\mathrm{HDL}_{3}$. We suggest that this increase in PON-1 activity would enhance the antiatherogenic potential of HDL in this T2D population.

With regards to LCAT, similarly to PON-1, this enzyme is mainly associated with $\mathrm{HDL}_{3}$, and its antioxidant property is related to it proton donating property $[15,33]$. Therefore, as the activity of LCAT has previously been reported to be decreased in subjects with T2D [34], we have now shown that increased F\&V intake augmented its activity within serum and particularly in $\mathrm{HDL}_{3}$ in this $\mathrm{T} 2 \mathrm{D}$ population. This increase in LCAT's activity may be related to the proton donating capacities of the additional F\&V derived antioxidants, thus illustrating another antiatherogenic effect of increased F\&V intake.

\section{$\mathrm{BMI}$, inflammation and the role of increased $\mathrm{F} \& \mathrm{~V}$ intake}

We must address the fact that BMI increased in the subjects randomised to the $\geq 6$-portion intervention, in spite of the diets being designed and appearing isocalorific in both groups $(p>005)$. However, as both carbohydrate and total sugars significantly increased following the $\geq 6$ portion intervention, and as these compounds are readily converted to fatty acids, this may have contributed to the increased BMI in this group, although a point to note is that these increases did not appear to influence the long term marker of glycaemic control, namely $\mathrm{HbA}_{1 \mathrm{C}}$, which was not different in the between group comparisons. Unfortunately, this increase in BMI may have negated a decrease in SAA, as there was only a trend for this inflammatory marker to decrease in $\mathrm{HDL}_{3}$ following the $\geq 6$-portion intervention $(p=0.133)$. This was not consistent with previous non-reported findings by our group, where SAA did decrease following increased $\mathrm{F} \& \mathrm{~V}$ intake, although in this study BMI remained stable. Therefore, the increase in BMI $(0.3 \mathrm{Kg} /$ $\mathrm{m}^{2}$ ) in the $\geq 6$-portion group may have augmented SAA release, especially as SAA is released chronically from hypertrophic adipocytes [5]. Thus, the overall effect would be that any SAA-lowering effects afforded by the increased $F \& V$ intake would have been opposed by this additional adipose tissue. Overall, this finding raises a note of caution regarding the need to ensure that the composition of a F\&V intervention should be closely monitored, to ensure that BMI remains stable. Nevertheless, this increase in BMI did not appear to impact on the enzymes examined in this current study.

Finally, we must consider the non-significant $(\mathrm{p}=0.295)$ gender difference between the two groups at randomisation, where $20 \%$ of the subjects in the 1-portion intervention were female, while females made up $38.5 \%$ of the subjects in the $\geq 6$-portion intervention. However, although females usually attach greater importance to 
healthy eating [35], all subjects appeared to adhere to the intervention group to which they were assigned, irrespective of gender. This was shown by the similar self-reported $\mathrm{F} \& \mathrm{~V}$ intake and changes in carotenoids in both genders from each of the two groups (results not shown).

\section{Conclusion}

In subjects with $\mathrm{T} 2 \mathrm{D}$, increased $\mathrm{F} \& \mathrm{~V}$ consumption resulted in an increase in carotenoid levels and the activities of PON-1 and LCAT, which was particularly apparent in $\mathrm{HDL}_{3}$, which we suggest would augment the antioxidant capabilities of this lipoprotein and would enhance its antiatherogenic potential. This study provides mechanistic support for the effectiveness of increased F\&V intake, which may be a realistic lifestyle intervention to help lower the risk of T2D and its associated CVD.

\section{Abbreviations \\ Al: (apo Al) Apolipoprotein; BMI: body mass index; CVD: Cardiovascular disease; F\&V: Fruit and vegetable; FSA: Food Standards Agency; HDL: High-density lipoprotein; HPLC: High performance liquid chromatography; hsCRP: High-sensitivity C-reactive protein; LCAT: Lecithin cholesterol acyltransferase; PON-1: Paraoxonase-1; RCT: Reverse cholesterol transport; T2D: Type 2 diabetes.}

\section{Competing interests}

The authors declare that they have no competing interest.

\section{Authors' contributions}

JAD undertook the laboratory analyses for this study and drafted the manuscript. CM (formally McLaughlin) was responsible for the recruitment and running of the primary study and commented on the current manuscript. DMcC supervised CM in the primary analyses and also commented on the current manuscript. JW was involved in the primary analyses and also commented on the current manuscript. IY supervised CM in the primary analyses and also commented on the current manuscript. JMCE was responsible for the study concept, supervised JAD and also had the final say in manuscript preparation and submission. All authors read and approved the final manuscript.

\section{Acknowledgments \\ Foremost, we would like to thank Dr Ciara Mulligan (formally McLaughlin) who was responsible for the recruitment and running of the primary study, which provided the samples for these secondary analyses. We would also like to thank the staff at the Regional Centre for Endocrinology and Diabetes at the Royal Victoria Hospital, Belfast, UK, and the participants who took part in this study. We would also like to thank Mrs Kathy Pogue for assisting with the HPLC analysis.}

\section{Author details}

${ }^{1}$ Centre for Public Health, Queen's University Belfast, Pathology Building, Grosvenor Road, Belfast BT12 6BJ, UK. ${ }^{2}$ Regional Centre for Endocrinology and Diabetes, Royal Victoria Hospital, Belfast BT12 6BA, UK.

Received: 19 November 2013 Accepted: 9 January 2014

Published: 14 January 2014

\section{References}

1. Hamano M, Saito M, Eto M, Nishimatsu S, Suda H, Matsuda M, Matsuki M, Yamamoto S, Kaku K: Serum amyloid A, C-reactive protein and remnantlike lipoprotein particle cholesterol in type 2 diabetic patients with coronary heart disease. Ann Clin Biochem 2004, 41(2):125-129.

2. World Health Organisation: Cardiovascular Disease; 2012. http://www.who. int/mediacentre/factsheets/fs317/en/index.html.
3. Zhang $Q$, Zhang Y, Feng H, Guo R, Jin L, Wan R, Wang L, Chen C, Li S: High density lipoprotein (HDL) promotes glucose uptake in adipocytes and glycogen synthesis in muscle cells. PLoS One 2011, 6(8):e23556.

4. Mastorikou M, Mackness B, Liu Y, Mackness M: Glycation of paraoxonase-1 inhibits its activity and impairs the ability of high-density lipoprotein to metabolize membrane lipid hydroperoxides. Diabet Med 2008, 25(9):1049-1055.

5. Hatanaka E, Monteagudo PT, Marrocos MS, Campa A: Interaction between serum amyloid $A$ and leukocytes - a possible role in the progression of vascular complications in diabetes. Immunol Lett 2007, 108(2):160-166.

6. Khovidhunkit W, Shigenaga JK, Moser AH, Feingold KR, Grunfeld C: Cholesterol efflux by acute-phase high density lipoprotein: role of lecithin: cholesterol acyltransferase. J Lipid Res 2001, 42(6):967-975.

7. Mackness B, Mackness M: Anti-inflammatory properties of paraoxonase-1 in atherosclerosis. Adv Exp Med Biol 2010, 660:143-151.

8. Villegas R, Shu XO, Gao YT, Yang G, Elasy T, Li H, Zheng W: Vegetable but not fruit consumption reduces the risk of type 2 diabetes in chinese women. J Nutr 2008, 138(3):574-580.

9. Panagiotakos DB, Pitsavos C, Kokkinos P, Chrysohoou C, Vavuranakis M, Stefanadis $C$, Toutouzas P: Consumption of fruits and vegetables in relation to the risk of developing acute coronary syndromes; the CARDIO2000 case-control study. Nutr J 2003, 8:2-2.

10. Cooper AJ, Sharp SJ, Lentjes MA, Luben RN, Khaw KT, Wareham NJ, Forouhi NG: A prospective study of the association between quantity and variety of fruit and vegetable intake and incident type 2 diabetes. Diabetes Care 2012, 35:1293-1300.

11. McEneny J, Wade L, Young IS, Masson L, Duthie G, McGinty A, McMaster C, Thies F: Lycopene intervention reduces inflammation and improves HDL functionality in moderately overweight middle-aged individuals. J Nutr Biochem 2013, 24(1):163-168.

12. Asgard R, Rytter E, Basu S, Abramsson-Zetterberg L, Moller L, Vessby B: High intake of fruit and vegetables is related to low oxidative stress and inflammation in a group of patients with type 2 diabetes. Scand J Food Nutr 2007, 51(4):149-158.

13. Blum S, Aviram M, Ben-Amotz A, Levy Y: Effect of a Mediterranean meal on postprandial carotenoids, paraoxonase activity and C-reactive protein levels. Ann Nutr Metab 2006, 50(1):20-24.

14. National Health Service: 5 A Day Portion Sizes; 2011. http://www.nhs.uk/ livewell/5aday/documents/downloads/5aday_portion_guide.pdf.

15. McPherson PA, Young IS, McKibben B, McEneny J: High density lipoprotein subfractions: isolation, composition, and their duplicitous role in oxidation. J Lipid Res 2007, 48(1):86-95.

16. McEneny J, Loughrey CM, McNamee PT, Trimble ER, Young IS: Susceptibility of VLDL to oxidation in patients on regular haemodialysis. Atherosclerosis 1997, 129(2):215-220.

17. Craft NE: Carotenoid reversed-phase high-performance liquid chromatography methods: reference compendium. Methods Enzymol 1992, 213:185-205.

18. Hasselwander O, McEneny J, McMaster D, Fogarty DG, Nicholls DP, Maxwell AP, Young IS: HDL composition and HDL antioxidant capacity in patients on regular haemodialysis. Atherosclerosis 1999, 143(1):125-133.

19. Pearson TA, Mensah GA, Alexander RW, Anderson JL, 3rd Cannon RO, Criqui M, Fadl YY, Fortmann SP, Hong Y, Myers GL, Rifai N, Smith SC Jr, Taubert K, Tracy RP, Vinicor F, Centres for Disease Control and Prevention; American Heart Association: Markers of inflammation and cardiovascular disease: application to clinical and public health practice: A statement for healthcare professionals from the Centres for Disease Control and Prevention and the American Heart Association. Circulation 2003, 107:499-511.

20. McEvoy CT, Temple N, Woodside JV: Vegetarian diets, low-meat diets and health: a review. Public Health Nutr 2012, 15(12):2287-2294.

21. Di Mascio P, Kaiser S, Sies H: Lycopene as the most efficient biological carotenoid singlet oxygen quencher. Arch Biochem Biophys 1989, 274(2):532-538.

22. Nielsen F, Mikkelsen BB, Nielsen JB, Anderson HR, Grandjean P: Plasma malondialdehyde as biomarker for oxidative stress: reference interval and effects of life-style factors. Clin Chem 1997, 43(7):1209-1214.

23. Fenercioglu AK, Saler T, Genc E, Sabuncu H, Altuntas Y: The effects of polyphenol-containing antioxidants on oxidative stress and lipid peroxidation in Type 2 diabetes mellitus without complications. J Endocrinol Invest 2010, 33(2):118-124. 
24. Juanola-Falgarona M, Salas-Salvadó J, Estruch R, Portillo MP, Casas R, Miranda J, Martínez-González MA, Bulló M: Association between dietary phylloquinone intake and peripheral metabolic risk markers related to insulin resistance and diabetes in elderly subjects at high cardiovascular risk. Cardiovasc Diabetol 2013, 12:7.

25. Fernemark $\mathrm{H}$, Fernemark $\mathrm{H}$, Jaredsson C, Bunjaku B, Rosenqvist U, Nystrom $\mathrm{FH}$, Guldbrand H: A randomized cross-over trial of the postprandial effects of three different diets in patients with type 2 diabetes. PLoS One 2013, 8(11):e79324.

26. Ortega-Azorín C, Sorlí JV, Asensio EM, Coltell O, Martínez-González MÁ, Salas-Salvadó J, Covas MI, Arós F, Lapetra J, Serra-Majem L, Gómez-Gracia E, Fiol M, Sáez-Tormo G, Pintó X, Muñoz MA, Ros E, Ordovás JM, Estruch R, Corella D: Associations of the FTO rs9939609 and the MC4R rs17782313 polymorphisms with type 2 diabetes are modulated by diet, being higher when adherence to the Mediterranean diet pattern is low. Cardiovasc Diabetol 2012, 11:137.

27. Hockerstedt A, Tikkanen MJ, Jauhiainen M: LCAT facilitates transacylation of 17 beta-estradiol in the presence of HDL3 subfraction. J Lipid Res 2002, 43(3):392-397.

28. Bergmeier C, Siekmeier R, Gross W: Distribution spectrum of paraoxonase activity in HDL fractions. Clin Chem 2004, 50(12):2309-2315.

29. Aviram M, Rosenblat M, Billecke S, Erogul J, Sorenson R, Bisgaier CL, Newton RS, La Du B: Human serum paraoxonase (PON 1) is inactivated by oxidized low density lipoprotein and preserved by antioxidants. Free Radic Biol Med 1999, 26(7-8):892-904.

30. Calabresi L, Franceschini G: Lecithin:cholesterol acyltransferase, highdensity lipoproteins, and atheroprotection in humans. Trends Cardiovasc Med 2010, 20(2):50-53.

31. Abbott CA, Mackness MI, Kumar S, Boulton AJ, Durrington PN: Serum paraoxonase activity, concentration, and phenotype distribution in diabetes mellitus and its relationship to serum lipids and lipoproteins. Arterioscler Thromb Vasc Biol 1995, 15(11):1812-1818.

32. Aviram M, Dornfeld L, Rosenblat M, Volkova N, Kaplan M, Coleman R, Hayek T, Presser D, Fuhrman B: Pomegranate juice consumption reduces oxidative stress, atherogenic modifications to $\mathrm{LDL}$, and platelet aggregation: studies in humans and in atherosclerotic apolipoprotein E-deficient mice. Am J Clin Nutr 2000, 71(5):1062-1076.

33. Vohl MC, Neville TA, Kumarathasan R, Braschi S, Sparks DL: A novel lecithincholesterol acyltransferase antioxidant activity prevents the formation of oxidized lipids during lipoprotein oxidation. Biochemistry 1999, 38(19):5976-5981.

34. Nakhjavani M, Asgharani F, Khalilzadeh O, Esteghamati A, Ghaneei A, Morteza A, Anvari M: Oxidized low-density lipoprotein is negatively correlated with lecithin-cholesterol acyltransferase activity in type 2 diabetes mellitus. Am J Med Sci 2011, 341(2):92-95.

35. Westenhoefer J: Age and gender dependent profile of food choice. Forum Nutr 2005, 57:44-51.

doi:10.1186/1475-2840-13-16

Cite this article as: Daniels et al:: A randomised controlled trial of increasing fruit and vegetable intake and how this influences the carotenoid concentration and activities of PON-1 and LCAT in HDL from subjects with type 2 diabetes. Cardiovascular Diabetology 2014 13:16.

\section{Submit your next manuscript to BioMed Central and take full advantage of:}

- Convenient online submission

- Thorough peer review

- No space constraints or color figure charges

- Immediate publication on acceptance

- Inclusion in PubMed, CAS, Scopus and Google Scholar

- Research which is freely available for redistribution 